\title{
UNEMPLOYMENT AND ECONOMIC GROWTH: IS THERE A RELATIONSHIP IN THE EUROPEAN UNION?
}

\section{Milen Velev*}

\begin{abstract}
The aim of this paper is to investigate the relationship between unemployment and economic growth in the European Union and in individual European countries. This allows to determine what the effect on the unemployment rate will be when there is a change in output. The European Union (28 countries) quarterly data used is for the period from 2000Q1 to 2017Q3. Regression analysis, co-integration analysis and a vector error correction model have also been used. The relationship between the unemployment rate and economic growth in the EU-28 for the period examined in this study is less pronounced in comparison with the other countries. A negative relationship between economic growth and a change in the unemployment rate is obtained for all the countries in the European Union (28 countries). During each stage of the period studied, the effect of hysteresis on the labour market grew. The results from the statistical analysis show that the data on economic growth and the change in the rate of unemployment in the EU-28 are co-integrated. The validity of Okun's Law for the economy of the European Union is confirmed although during the period studied the European economy went through several phases of the economic cycle.
\end{abstract}

Keywords: unemployment rate, economic growth, Okun's Law, European Union

JEL Classification: E24, E32, O40, O52

\section{Introduction}

The problems related to the dependencies that exist between unemployment and economic growth are of great significance to every macroeconomic policy. The global economic and financial crisis severely affected the economies of the European countries and recovery was slow and difficult. The economic crisis also affected each individual economy in a different way and led to a considerable differentiation in the unemployment rates and the output of the individual countries in the European Union. One of the main objectives of the macroeconomic policies implemented is the achievement of stable economic growth and a decrease in the unemployment rates of the individual countries and the European economy. In elaborating these policies, it is crucial that the existing specific relationship between unemployment and economic growth should be clarified at both national and EU levels.

Okun's Law expresses the negative relationship between the deviation of the current output from the real output on the one hand, and, on the other hand, the deviation of the actual rate of unemployment from its natural rate. The existence of this relationship was empirically established by Okun (1962) for the economy of the USA, which, during the time period investigated, was characterised by a stable and upward development as well as

* Prof. Dr. Asen Zlatarov University, Faculty of Social Sciences, Burgas, Bulgaria (milen.velev@gmail.com). 
a low rate of unemployment. After this relationship was derived, it became a standard tool for developing macroeconomic policies and forecasts. Okun's equation is often employed to transform unemployment increase data into output decrease data and vice versa. As regards the data on the USA, the estimated coefficients remain comparatively stable although in the studies conducted on other countries, in most cases, the coefficients are less stable and in general, the results are less satisfactory (Schnabel, 2002).

Economists often use Okun's law in their forecasts, assuming that the relationship between the growth of the GDP and the changes in the rate of unemployment will manifest itself in a similar way both in the future and in the past. It should be noted that Okun's law is a statistical relationship rather than a structural feature of the macroeconomic system. Various studies (Schnabel, 2002; Daly et al., 2014) show that the specific quantitative relationship between the changes in output and the rate of unemployment varies considerably over time and during the different phases of the economic cycle.

\section{Literature Review}

Okun's Law is of great importance at both theoretical and empirical levels. Theoretically, Okun's Law together with the Phillips curve is a key element in deriving the aggregate demand curve. Empirically, Okun's coefficient is a useful tool for developing and applying macroeconomic policies and forecasting the results from implementation (Harris and Silverstone, 2001). Over the past few decades, many empirical studies have investigated this law with findings which, overall, tend to support it in most cases (Adanu, 2005).

The quantitative relationship obtained shows a change in the unemployment rate, which is two to three times weaker compared to the relative change in output. This is basically related to the following factors (Pirimova, 2007). In the case of a substantial and lasting decrease in output, the unemployment rate rises but at a slower pace due to a variety of reasons - for example, some of those made redundant move to independent entrepreneurial activity; others abandon any participation in work activity (i.e. join the ranks of those outside the workforce); and others emigrate. Any considerable and longlasting shrinkage in output results in decreasing the labour productivity of the persons engaged in the economy. Among the reasons for this are both the growing number of persons employed part-time and the increasing number of cases in which employed persons are engaged in types of manufacturing activities that do not correspond with their level of education and professional qualifications. The number of persons employed part-time increases due to the decreasing volumes of output, the smaller revenues and profits made, and the reduction of expenses pursued. Pressed by the lack of income and confronted with the limited supply of jobs, unemployed people are willing to accept jobs that do not match their qualifications. In most cases, employment rises with an increase in output, and unemployment decreases accordingly, although at a slower pace. The increase in output may be due to an increase in labour productivity and/or capital rather than a rise, for example, in employment because of more efficient labour resources management and organisation, technology improvement, etc. It is possible that employment and unemployment recover to levels higher than the pre-crisis levels. One of the reasons for this is the existence of hysteresis in the labour market. Hysteresis shows the dependence of the state of equilibrium of a given dynamic economic system on the way in which this system has reached this state. Hysteresis manifests itself after negative shocks when unemployment remains permanently higher. One of the main reasons for hysteresis is 
long-term unemployment and the related loss of qualifications and skills, deterioration of human capital, and employers' unwillingness to hire long-term unemployed persons, etc.

According to various studies, although Okun's relationship is stable over the long run, over shorter periods it can vary considerably. For example, Schnabel (2002), Meyer and Tasci (2012), Owyang and Sepkhposyan (2012), IMF (2010) and McKinsey (2011) find that Okun's Law is unstable over time. In contrast, Ball et al. (2017), Daly et al. (2014) find that Okun's Law is a stable relationship, which does not change during economic crises.

Despite the numerous scientific publications in the researched area, most only address data regarding a particular national economy. However, in recent years, certain studies - for example, Lee (2000), Dogru (2013), Perman and Tavera (2005), Anderton et al. (2014), Economou and Psarianos (2016), have attempted to overcome this shortcoming by applying a cross-country analysis of the relationship between unemployment and economic growth in the Eurozone, the European Union, the Organisation for Economic Co-operation and Development, etc.

The main aim of this paper is to investigate the relationship between unemployment and economic growth at the level of the European Union as well as the individual national economies. In this way, the effect on the unemployment rate when there is a change in output will be established. Knowledge of this relationship is important with a view to the efficient application of the macroeconomic policies.

Okun's Law can be expressed in the so-called gap version and the difference version. In this study, the difference version approach is applied, in which chain indices are calculated against a preceding period (with a variable base). This approach makes it possible to better trace and analyse the individual sub-periods of upswing and downswing in the macroeconomic activity of the European economy.

\section{Theoretical Framework}

In general terms, economic growth is a process of successive increases in the real output. Depending on the length of the time period, the theory basically employs two approaches to characterise economic growth. According to the first approach, economic growth represents the long-term positive trend in the dynamics of the gross domestic product (GDP) and shows the long-term trend in the change of the productive potential of the economy (so-called long-term growth). According to the second approach, which is applicable in the short term as well as the long term, economic growth shows the changes in the real values of the GDP and the reasons for growth (so-called short-term growth). In this paper, the second approach is used to measure economic growth. Unemployment is measured by means of two indices - as an absolute amount, which represents the number of unemployed people, and as a rate. In this study, unemployment is estimated through the coefficient of unemployment as a percentage of the active population.

Okun's Law is expressed by the following formula:

$$
u_{t}-u^{*}=\alpha\left(\frac{Y_{t}-Y^{*}}{Y^{*}} \cdot 100\right)+\omega_{t},
$$

where $u_{t}$ is the current level of unemployment, $Y_{t}$ is the current real GDP, $\alpha$ is Okun's coefficient, $\omega_{t}$ is the error term, $Y^{*}$ is potential GDP, $u^{*}$ is the natural rate of unemployment (the symbol $\left({ }^{*}\right)$ shows the long-run level), $t$ - number of periods (quarters). If we take the 
differences between the quantities on the two sides of the equation (1) and assume that the natural level of unemployment is constant and potential output grows at a constant rate, then we obtain:

$$
\Delta u=\beta+\alpha\left(\frac{\Delta Y}{Y_{t-1}} \cdot 100\right)+\varepsilon_{t},
$$

where $\Delta Y=Y_{t}-Y_{t-1}$ is the change in actual output from one quarter to the next, $\Delta u=u_{t}-u_{t-1}$ is the change in actual unemployment from one quarter to the next, $\beta$ is the intercept, $\varepsilon_{t}=\Delta \omega_{t}$. By means of formula (2), the relationship between the rate of output growth and the change in the level of unemployment is expressed. The coefficient $\alpha$ expresses the sensitivity with which output changes when there is a change in the level of unemployment. If we put $\Delta u=0$, then we will get: $0=\beta+\alpha \frac{\Delta Y}{Y_{t+1}} \cdot 100+\varepsilon_{t}$. Therefore, the expression $-\frac{\beta}{\alpha}$ shows what the percentage growth of the real GDP should be for unemployment to stay at the same level (against the preceding period). If we put $\Delta Y=0$, then we get: $\Delta u=\beta+\varepsilon_{t}$. Therefore, the coefficient $\beta$ shows by how many percentage points (pp) the level of unemployment will decrease/increase if the real GDP remains constant.

The different studies - Schnabel (2002), Perman and Tavera (2007), Knotek (2007), Ball et al. (2015; 2017), Daly et al. (2017) - show that the absolute value of Okun's coefficient, which was originally considered to be close to 0.3 , varies considerably over time, and during the different stages of the economic cycle it also depends on the models applied and can be quite different. Okun's coefficient depends on a large number of factors: for example, on the ratio between the amounts of labour and capital used in the production process; the industrial structure of the economy (the relative share of labour-intensive and capital-intensive industries); the proportion between extensive and intensive growth factors; the structure of a company (relative share of small, mediumsized and large enterprises); the changes in the structure of unemployment; the relative share of hidden economy; the growth of the labour force and labour productivity, etc. These factors are different for individual countries. This is why it is highly probable that Okun's coefficient could also be different in individual countries.

The particular quantitative relationship between unemployment and economic growth expressed by formula (2) is estimated and analysed by means of econometric models, applied at the level of the European economy and using quarterly data. Further on, we will use the following symbols: $U m R_{t}=\Delta u ; G r R_{t}=\frac{\Delta Y}{Y_{t-1}} \cdot 100$.

\section{Information Sources and Limitations in Conducting the Study}

Information from Eurostat has been used in conducting this study. The present study has the following limitations:

1. The information presented is for the period from 2000Q1 to 2017Q3.

2. The study covers data on all 28 countries that are currently member-states of the European Union.

3. The study is based on official and publicly available information.

4. The analysis does not include important stages such as macroeconomic policies implemented, operating institutions, the influence of the demographic processes, the structural characteristics of the national economies, etc. 


\section{A Study of the Relationship between Unemployment and Economic Growth}

The study begins by examining the dynamics of the real GDP and the rate of unemployment with quarterly data on the European economy for the period 2000Q1-2017Q3 being used in the process.

\section{Figure 1 | Real GDP (Chain linked volumes (2010), million euro) of the EU-28 for the period} 2000Q1-2017Q3'

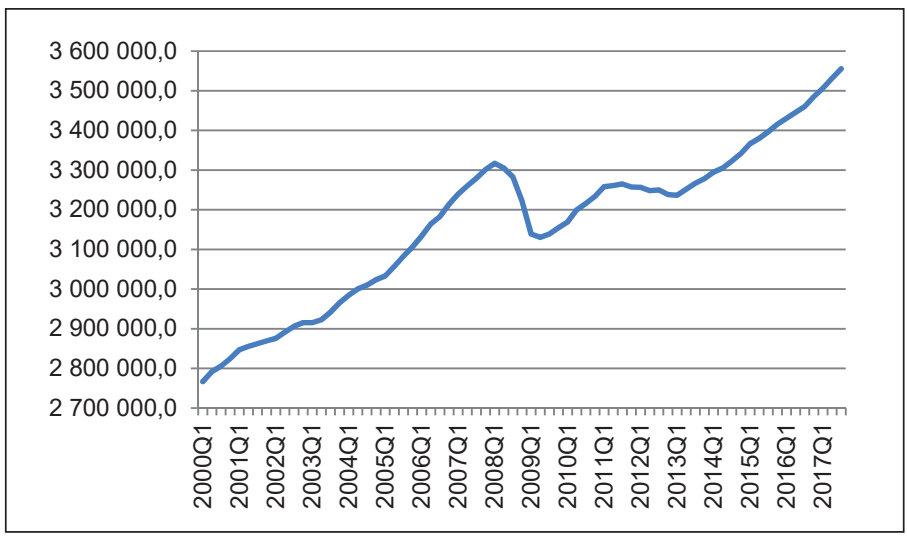

Source: Eurostat

Figure 2 | Unemployment rate (percentage of the active population) in the EU-28 for the period 2000Q1-2017Q3 ${ }^{2}$

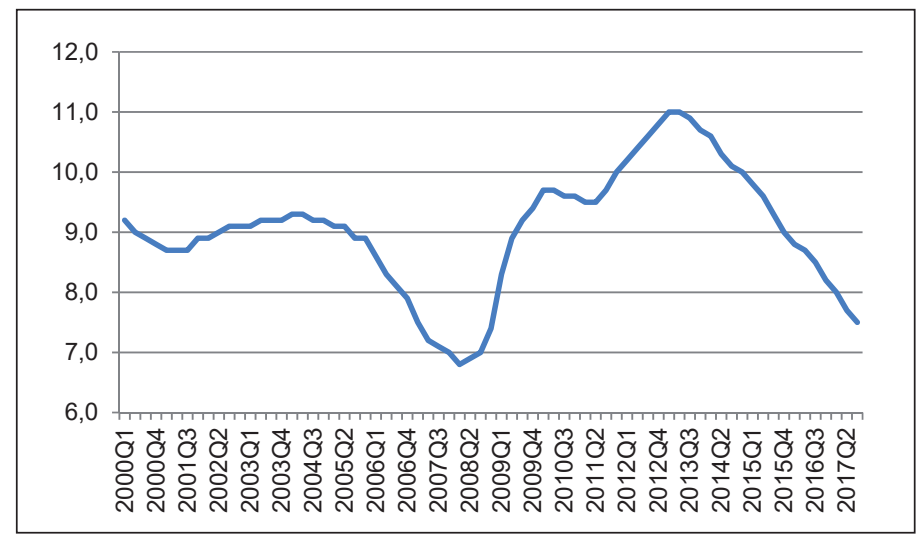

Source: Eurostat

As seen in Figure 1, during the period studied, the European economy went through several phases of the economic cycle - expansion, peak, contraction, trough, recovery. Despite the cyclic fluctuations, a distinct trend of an increase in the real GDP is observed.

1 The time series are seasonally, and calendar adjusted.

2 The time series are seasonally adjusted. 
The real GDP had the lowest value at the beginning of the period studied 2000Q1 (€2766853.8 million) and reached the highest value at the end of the period studied 2017Q4 (€3555510 million). For the period studied, the real GDP of the EU-28 grew by $€ 788656.2$ million or by $28.5 \%$. In the periods 2003Q1, 2008Q2-2009Q2, 2011Q4-2012Q2, and 2012Q4-2013Q1 there was a fall in the real GDP compared to the preceding quarter, and for the rest of the periods, there was a rise in the real GDP of the EU-28 (compared to the preceding quarter). The considerable fall in 2008-2009 and in the subsequent periods was due to the influence of the global economic crises (The Great Recession) and the slow and difficult recovery from the negative consequences.

As can be seen in Figure 2, during the period studied, the unemployment rate fluctuated considerably. The rate of unemployment was the highest in 2013Q1-Q2 (11.0\%) and the rate of unemployment had been the lowest immediately before the global economic crisis affected the European economy - $2008 \mathrm{Q} 1$ (6.8\%). According to the graph in Figure 2 , the period studied can be notionally divided into four sub-periods: During the first subperiod (2000Q1-2004Q4), the unemployment rate remained relatively steady - about 9\%. During the second sub-period (2005Q1-2008Q1), the unemployment rate in the EU-28 decreased by 2.3 percentage points ( $\mathrm{pp}$ ) and reached its lowest value. During the third subperiod, as a result of the negative influence of the global economic crisis, unemployment in the EU-28 grew considerably (by $4.1 \mathrm{pp}$ ), reaching its highest value (from $6.9 \%$ in 2008Q2 to 11\% in 2013Q2). Only for the period 2010Q1-2011Q3 was a certain steadiness and even a slight decline in this rate observed although the trend proved short-lived. During the fourth sub-period, the unemployment rate decreased by $3.4 \mathrm{pp}$ (from $10.9 \%$ in 2013Q3 to $7.5 \%$ in 2017Q3).

\subsection{Regression Analysis}

The study continues with the estimation of the relationship between unemployment and economic growth in the European Union including the 28 member-states (EU-28). The differences in the quantities (i.e. $\Delta Y, \Delta u$ ) are in comparison with the preceding quarter.

Figure 3 | Comparison between the quantities $G r R_{t}$ and $U m R_{t}$ for the EU-28 for the period 2000Q1-2017Q3 (a change in comparison with the preceding quarter)

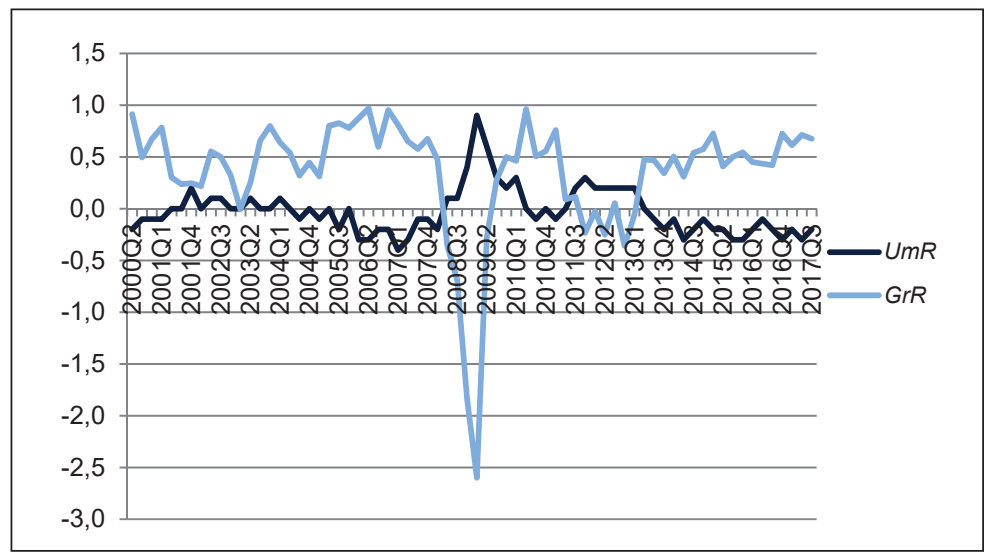

Source: Eurostat and author's own calculations 
The results from the regression analysis are presented in Figure 4. The numerical value of the Durbin-Watson test statistic is equal to $d=0.844$. The null hypothesis of the DW-test is the assumption that there is no autocorrelation in the residuals. On comparing the empirical values with the theoretical values, it has been found that there is statistical evidence that the error terms are positively autocorrelated, because $d<d L=1.583$, $(d L=1.583 ; d U=1.641)$.

Figure 4 | Relationship between unemployment and economic growth in the EU-28 for the period 2000Q1-2017Q3 (linear regression model)

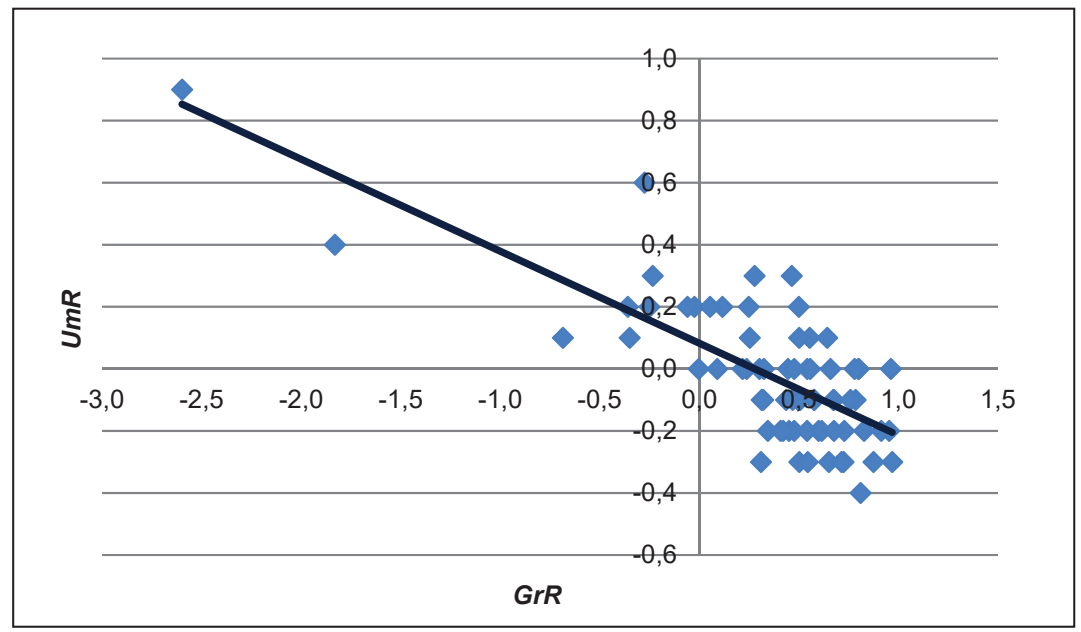

Source: Eurostat and author's own calculations

The Durbin-Watson test estimates the presence of a first-order autocorrelation. To estimate a higher-order serial correlation then the Breusch-Godfrey test (LM Test), based on the Lagrange multipliers, is used. In the new regression equation, besides the existing explanatory variables, lag residuals 1 and 2 are added. The results from the LM Test show that we cannot reject the null hypothesis of the existence of a second-order autocorrelation.

One of the most common reasons for autocorrelation is related to the estimation of the static regression models in which time is not explicitly or implicitly present. To remove the autocorrelation, a new regression model is constructed, which includes the variables reflecting the lag values of a part of the variables (dynamisation of the model). The economic processes are marked by inertia in which the state of the variables from the preceding periods affects their current state. It is logical to assume that the dynamics of unemployment in the current period depends on the dynamics of this indicator during the preceding period, i.e. on the inertia of the economic process. The new specification of the regression equation is as follows:

$$
U m R_{t}=\beta+\alpha_{1} G r R_{t}+\alpha_{2} U m R_{t-1}+\varepsilon_{t} .
$$

There are resemblances but also fundamental differences between the dynamic version of Okun's Law and its original form. The dynamic version reflects not only the current correlation between the rate of unemployment and economic growth but also 
takes into consideration the influence of past values. The main drawback of the dynamic version is that it does not have the same simple interpretation as the original version of Okun's Law (Knotek, 2007).

The results from the regression analysis are presented in Table 1.

Table 1 | Results from the regression analysis of the variables: $U m R_{t}$ (dependent variable); $G r R_{t}$; $U m R_{t-1}$

\begin{tabular}{|c|c|c|c|c|}
\hline Variable & Coefficient & Std. Error & t-Statistic & P-value \\
\hline$a_{1}$ & -0.197 & 0.024 & -8.130 & 0.000 \\
\hline$a_{2}$ & 0.557 & 0.061 & 9.126 & 0.000 \\
\hline$\beta$ & 0.060 & 0.015 & 4.102 & 0.000 \\
\hline
\end{tabular}

Source: Author

The results obtained are better than those in the preceding regression equation (the coefficient of determination is higher, and the standard error of regression and the sum of squared residuals are lower. The result obtained for the F-statistic is 134.922 with p-value 0.000). The DW statistic, in this case, is invalid because the dependent variable is included as lagged explanatory variable 1. To test the existence of a first-order serial correlation, the Breusch-Godfrey test is used. The conclusion is that, in this case, we cannot reject the null hypothesis of a lack of autocorrelation in the residuals. Therefore, the reason for the autocorrelation in the static model of the examined relationship is the non-inclusion of variables that account for the dynamics of the relationship between the unemployment rate and economic growth. The presence of heteroscedasticity has been estimated using the Breusch-Pagan-Godfrey test. The results from the test provide the reason to fail to reject the null hypothesis of homoscedasticity.

The check that the residuals are normally distributed has been made using the JarqueBera statistic. According to the results obtained, we can assume that the residuals are normally distributed. The coefficient $\alpha_{1}$ before the variable $G r R_{t}$ expresses the strength of the response of the unemployment rate to a change in output. Therefore, Okun's coefficient for the EU-28 is equal to $\alpha_{1}=-0.20$. The coefficient $\alpha_{2}=0.56$ before the variable $U m R_{t-1}$ expresses the sensitivity to a change in the unemployment rate during the current quarter compared with the changes in this indicator during the preceding quarter. The existence of a high-degree of the relationship between the current and previous rates of unemployment shows the presence of hysteresis in the labour market. The interpretation of the coefficients of the regression equation shows that if the real GDP grows by $1 \%$, and the change in the unemployment rate is equal to zero $\left(U m R_{t-1}=0\right)$, then the current unemployment rate will decrease by $0.14 \mathrm{pp}\left(\beta+\alpha_{1}=-0.14\right)$. In this case, in order to prevent the unemployment rate from increasing $\left(U m R_{t}=0\right)$, the GDP needs to grow by $0.30 \%$. For the unemployment rate to decrease by $1 \mathrm{pp}$, the GDP needs to grow by $5.38 \%$.

According to the linear regression model obtained, if the real GDP does not change, then the current unemployment rate will be determined through this formula: $U m R_{t}=0.06+0.56 \cdot U m R_{t-1}+\varepsilon_{t}$. 
Since 2013Q3, the unemployment rate in the EU-28 has been showing a constant downward trend by $0.2 \mathrm{pp}$ per quarter on average. Therefore, the regression equation (3) will be: $U m R_{t}=-0.05-0.20 \cdot G r R_{t}+\varepsilon_{t}$. Under these conditions, the stimulating policies aimed at restraining unemployment have to take into consideration the following circumstances: First, a $1 \%$ increase in the GDP will lead to a decrease in the unemployment rate by $0.25 \mathrm{pp}$; Second, if the GDP decreases by $0.26 \%$, then the rate of unemployment will remain steady, it will not grow. Third, the rate of unemployment in the EU-28 for 2017Q3 was 7.5\%. For the rate of unemployment to decrease by 1 pp, the GDP should grow by $4.81 \%$.

\subsection{Cointegration Analysis}

Before the cointegration analysis is applied, the stationarity of the output data must be tested to find the order of integration of the time series. The stationarity of the data for the variables $U m R_{t}$ and $G r R_{t}$ for the EU-28 has been checked using the augmented DickeyFuller test (ADF). The results are presented in Table 2.

Table $2 \mid$ Results for the stationarity of the variables $U m R_{t}, G r R_{t}$ and for the first differences D $\left(U m R_{t}\right), D\left(G r R_{t}\right)$ for the EU-28, according to the ADF-test

\begin{tabular}{|c|c|c|c|c|}
\hline ADF-statistic & $U m R_{t}$ & -2.983 & $D\left(U m R_{t}\right)$ & -9.109 \\
\hline P-value & & 0.144 & & 0.000 \\
\hline ADF-statistic & $G r R_{t}$ & -3.324 & $D\left(G r R_{t}\right)$ & -8.017 \\
\hline P-value & & 0.071 & & 0.000 \\
\hline
\end{tabular}

Null Hypothesis: The variable has a unit root.

Source: Author

The check of the data for $U m R_{t}$ and $G r R_{t}$ for the EU-28 with the ADF-test shows that these variables are non-stationary (Table 2).

In the economic theory, the non-stationarity of the data on unemployment is usually associated with the effect of hysteresis in the labour market and the presence of long-term unemployment (Mitchell, 1993; Prachowny, 1993; Dogru, 2013). According to the data from Eurostat, in 2016, 46.4\% of all unemployed persons or 4\% of the active population in the EU-28 were long-term unemployed. The issue of long-term unemployment is the most serious in countries such as Greece, Italy, Spain, Bulgaria, etc.

On checking the first differences in the output data for the two variables, it turns out that they are stationary, i.e. the data on the EU-28 is integrated of the same order 1 $\left(U m R_{t} \sim I(1), G r R_{t} \sim I(1)\right)$ (Table 2$)$. This allows for conducting a co-integration analysis by employing the Johansen test.

The number of lags of the variables must be preliminarily chosen in order to employ the Johansen test. For this purpose, various criteria of assessment are used (LR test statistic, Final prediction error, Akaike information criterion, Schwarz information criterion, Hannan-Quinn information criterion), combined with a residual correlation test if necessary. The results from the Johansen co-integration test for the variables $U m R_{t}$ and $G r R_{t}$ for the EU-28 are presented in Table 3. 
Table 3 | The results from the Johansen co-integration test for the variables $U m R_{t}$ and $G r R_{t}$ for the EU-28

\begin{tabular}{|c|c|c|c|c|c|}
\hline $\begin{array}{c}\text { Lags } \\
\text { interval }\end{array}$ & $\begin{array}{c}\text { Hypothesis for } \\
\text { the number of } \\
\text { cointegration } \\
\text { equations }\end{array}$ & $\begin{array}{c}\text { Trace } \\
\text { Statistic }\end{array}$ & P-value & $\begin{array}{c}\text { Existence of } \\
\text { a long-run } \\
\text { relationship }\end{array}$ & $\begin{array}{c}\text { Number of } \\
\text { cointegration } \\
\text { vectors }\end{array}$ \\
\hline 1 & None $^{*}$ & 27.881 & 0.000 & Yes & 2 \\
\hline & At most $1^{*}$ & 6.949 & 0.008 & & \\
\hline
\end{tabular}

* denotes rejection of the hypothesis at the 0.05 level

Source: Author

The existence of a long-run relationship between the unemployment rate and economic growth is confirmed by the presence of two co-integration vectors/equations. The coefficient expressing the long-run relationship between the variables is 1.618 (normalised co-integrating coefficient). The conclusion is that the two variables examined are co-integrated and there are two co-integration equations.

\subsection{Error Correction Model}

The next stage of the study is related to the construction and estimation of an error correction model. The examined time series are co-integrated, which allows the application of Vector error correction model (VECM). The following equation has been obtained:

$$
\begin{aligned}
& \mathrm{D}\left(U m R_{t}\right)=\mathrm{C}(1) *\left(U m R_{t}(-1)+0.658^{*} G r R_{t}(-1)-0.210\right)+\mathrm{C}(2) * \mathrm{D}\left(U m R_{t}(-1)\right)+ \\
& +\mathrm{C}(3) * \mathrm{D}\left(U m R_{t}(-2)\right)+\mathrm{C}(4) * \mathrm{D}\left(G r R_{t}(-1)\right)+\mathrm{C}(5) * \mathrm{D}\left(G r R_{t}(-2)\right)+\mathrm{C}(6) .
\end{aligned}
$$

The results from the VECM estimation are presented in Table 4.

Table 4 | Results from the VECM estimation

\begin{tabular}{|c|c|c|c|c|}
\hline & Coefficient & Std. Error & t-Statistic & P-value \\
\hline $\mathrm{C}(1)$ & -0.177 & 0.085 & -2.071 & 0.043 \\
\hline $\mathrm{C}(2)$ & -0.573 & 0.140 & -4.097 & 0.000 \\
\hline $\mathrm{C}(3)$ & -0.241 & 0.130 & -1.848 & 0.069 \\
\hline $\mathrm{C}(4)$ & -0.162 & 0.055 & -2.965 & 0.004 \\
\hline $\mathrm{C}(5)$ & -0.068 & 0.052 & -1.317 & 0.193 \\
\hline $\mathrm{C}(6)$ & -0.003 & 0.015 & -0.199 & 0.843 \\
\hline
\end{tabular}

Source: Author

The coefficient before the correction mechanism is $C(1)$. Its economic interpretation is that it determines the speed of adjustment towards long-run equilibrium. This coefficient must be statistically significant, and the sign must be negative. According to the results obtained, the coefficient $C(1)$ is negative and statistically significant. This means that there is a long-run causality running from $G r R_{t}$ to $U m R_{t}$, i.e. the change in the growth rate of the 
GDP has an influence on the dependent variable such as the change in the unemployment rate. The speed of adjustment of unemployment towards economic growth is not very high, which corresponds with the theoretical framework of the relationship studied.

To check if there is a short-run causality between the variable $G r R_{t}$ and $U m R_{t}$, the hypothesis $C(4)=C(5)=0$ has been tested using the Wald test. The results from the Wald statistic show that the null hypothesis of the equation $C(4)=C(5)=0$ must be rejected, i.e. there is a short-run causality from $G r R_{t}$ to $U m R_{t}$.

Finally, we will check if the choice of $U m R_{t}$ as a dependent variable in the model examined, is correct from a statistical point of view. The results from the Breusch-Godfrey test show that the null hypothesis of a lack of autocorrelation in the residuals cannot be rejected. The Breusch-Pagan-Godfrey test shows the presence of heteroscedasticity. The check if the residuals are normally distributed has been made by means of the JarqueBera statistic. According to the results obtained, it can be assumed that the residuals are normally distributed. Therefore, there is just one problem with this model, related to the presence of heteroscedasticity. It could be assumed that there are short-run and long-run causality from $G r R_{t}$ (economic growth) to $U m R_{t}$ (change in the unemployment rate).

\subsection{Okun's Coefficient in the Member States of the EU-28}

Figure A1 presents the correlograms of the relationship between the change in the unemployment rate $\left(U m R_{t}\right)$ and the growth rate of the GDP $\left(G r R_{t}\right)$ for the individual member states of the EU 28. A negative relationship between economic growth and the unemployment rate is obtained for all countries in the European Union. The coefficient of determination is the biggest for Spain $\left(R^{2}=0.6095\right)$, and the coefficient of determination is the smallest for Malta $\left(R^{2}=0.002\right)$. Okun's coefficient $\alpha$ varies widely for the individual countries. Figure 5 presents the values of Okun's coefficient $\alpha$ for the individual countries in the EU-28.

\section{Figure 5 | Okun's coefficient for the individual countries in the EU-28}

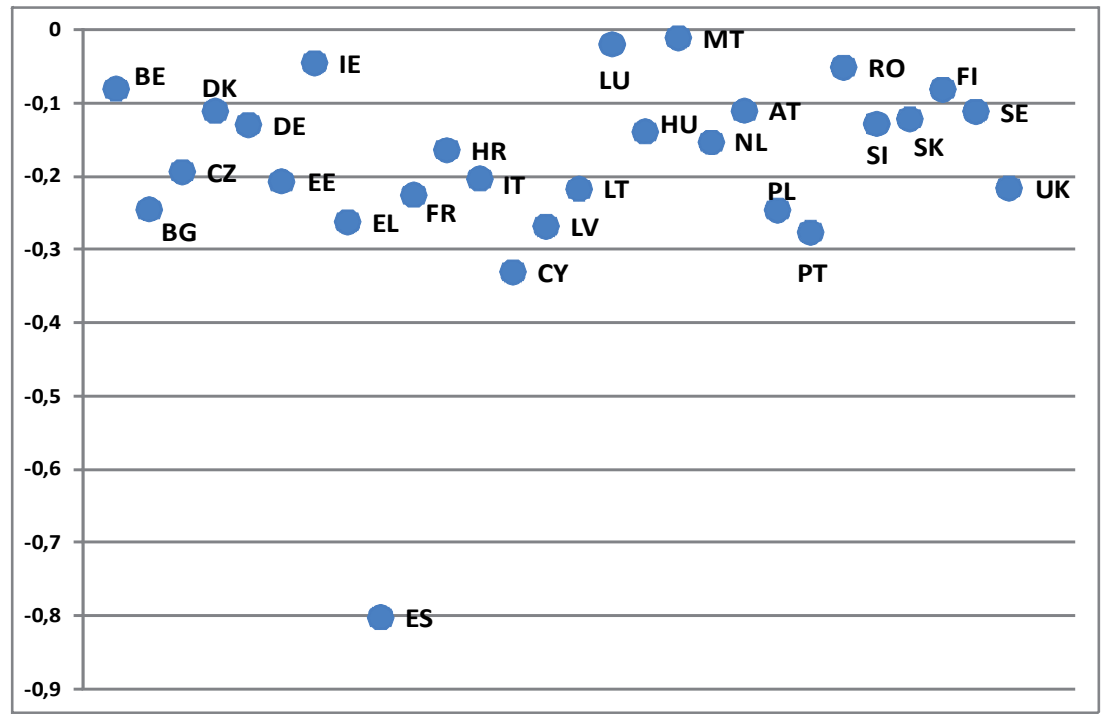

Source: Author 
As can be seen in Figure 5, the negative relationship is the most pronounced in Spain $(\alpha=-0.80)$, Cyprus $(\alpha=-0.33)$, Portugal $(\alpha=-0.28)$, and the negative relationship is the least pronounced in Malta $(\alpha=-0.01)$, Luxemburg, $(\alpha=-0.02)$, Ireland $(\alpha=-0.05)$. The unusually high incidence of temporary employment contracts can be one of the reasons for the high absolute value of Okun's coefficient for Spain, which makes it easier for the enterprises to adjust employment when output changes, which raises Okun's coefficient (Ball et al., 2017). One possible explanation is that the low absolute value of Okun's coefficient in some European countries is, for example, the influence of the effect of hysteresis on the labour market, the frequent use of foreign workers, as a result of which the unemployment rate remains relatively stable when output changes (Ball et al., 2017).

\section{Discussion and Conclusions}

The present study is focused on checking the validity of Okun's Law in the European Union with the difference version being applied. The present study has used the dynamic version of Okun's Law in which the change in the rate of unemployment in the current period depends on the economic growth during the current period and on the change in the rate of unemployment in a preceding period. The econometric models applied support the versions of Okun's Law that are less limited in time and include dynamic dependencies. In addition, the results obtained are practically applicable. For example, the forecasting of the rate of unemployment by applying Okun's Law is considerably improved, bearing in mind the dynamic relationship between unemployment and output growth. In the model considered, we have chosen unemployment as the dependent variable as it is in Okun's original article. As Barreto and Howland (1993) point out, this regression is used when the aim is to predict the unemployment rate when there is a change in the output level. In this case, Okun's coefficient on unemployment may prove to be overrated.

In macroeconomics, the existing dependencies are rarely called laws. In fact, Okun's Law is a statistical dependence, which is sometimes unstable and can be the subject of revision in a constantly changing macroeconomic system. The results of the study show that Okun's Law is valid for both the individual countries and the European Union despite the existing large differentiation in the rate of unemployment and the rates of economic growth in the different regions. Furthermore, during the period that has been investigated, the European economies went through different phases of the economic cycle. This means that Okun's Law is relatively stable and can be applied to forecast the rate of unemployment and economic growth in the European Union.

The empirical results show that Okun's coefficient on economic growth $\left(\alpha_{1}\right)$ for the EU-28, expresses the sensitivity with which the unemployment rate changes when the level of output changes is equal to $\alpha_{1}=-0.20$. In most studies, Okun's coefficient usually takes a mean value of about -0.4 . Therefore, the relationship between the unemployment rate and economic growth in the EU-28 for the period examined in this study is less pronounced in comparison with the rest of the countries.

It can be observed that the coefficient derived in the present study corresponds well with the values derived in previous studies of this type conducted by Freeman (2001), Sögner and Stiassny (2002), Ball et al. (2017), and Economou and Psarianos (2016). The coefficient derived is smaller in the absolute value than the one in Okun's original article (0.30). This coincides with the findings in the OECD report (2012) which state that in the Euro Area, Okun's coefficient has a value between the USA and Japan. 
The results obtained can be connected to the findings of Guisinger et al. (2018) and Nickell (1997), according to which the indices of the flexibility of the labour market (higher levels of educational achievement in the population, lower rate of unionisation, and a higher share of non-manufacturing employment) are important determinants of the differences in Okun's coefficient for the individual countries. As can be seen in some studies (Boman and Netzén Örn, 2017), the European economies are characterised by higher values of union density. Blanchard and Wolfers (2000) compare the European labour market with the labour market in the USA and find that the higher employment protection is one of the factors that increase the duration of unemployment in Europe and hence the unemployment rate. The more generous system of unemployment benefits reduces the incentives for job search, which also results in increasing the duration of unemployment. Siebert (1997) also discusses the issue of the greater duration of unemployment in Europe, emphasising the fact that the European countries adjusted worse to the accelerated global competition and the labour-saving technology developed in the 1990s. According to the findings of Guisinger et al. (2018), Blanchard and Wolfers (2000), the higher rate of longterm unemployment exerts an influence on Okun's dependence, and in this case, generates a lower absolute value of the coefficient.

Although Okun's Law is not as universal as, for example, the Law of Gravitation, the present study endorses the view that this law is relatively stable for the standards of macroeconomics and the reported deviations are exaggerated (e.g., see Ball et al., 2017). The article employs the traditional macro models in which the change in the aggregate demand causes short-term fluctuations of unemployment. The present article does not offer a direct explanation of the lower assessments of Okun's coefficient on economic growth for the European economy in comparison with the USA, for example. Traditional macroeconomics explains this fact with the expenditure to adjust employment to the change in aggregate demand. In this case, the results obtained can be interpreted as a consequence of the relatively high inelasticity of the European labour markets and the existing European legislation for employment protection. It is not clear whether the low coefficient of Okun will also arise out of other models of unemployment and economic growth. When developing and applying macroeconomic policies for encouraging economic growth and restricting unemployment, the results for the lower absolute value of Okun's coefficient and correspondingly the less pronounced dependence between these indices for the European economy should be taken into consideration.

From a political point of view, a conclusion can be made that in order to improve the competitiveness of the European economy, it is necessary to employ policies, on both national and European levels, aimed at decreasing unemployment and, at the same time, increasing productivity. In order to deal with this problem successfully, the considerable differences in the values of Okun's coefficient for the individual national economies should be taken into account (e.g., the absolute values of this coefficient are the highest in Spain, Cyprus, Portugal, and the lowest in Malta, Luxemburg, Ireland). It is obvious that politicians should keep these differences in mind when planning and applying suitable measures, specific to a given country.

In the countries in which the absolute value of Okun's coefficients obtained is low, a variety of short-term policies for managing the aggregate demand could be applied to decrease the rate of unemployment. In the countries in which the absolute value of Okun's coefficients is very high, the policies related to encouraging the aggregate supply would 
be more adequate (e.g., reforms in the tax and income system, aimed at increasing the incentives for employment; see Villaverde and Maza, 2008).

In the future, the scope of the analysis could be expanded by estimating the potential GDP and the natural rate of unemployment in the EU-28 and by employing the gap version of Okun's law.

\section{References}

Adanu, K. (2005). A Cross-Province Comparison of Okun's Coefficient for Canada. Applied Economics, 37(5), pp. 561-570. https://doi.org/10.1080/0003684042000201848

Anderton, R., Aranki, T., Bonthuis, B., and Jarvis, V. (2014). Disaggregating Okun's Law. Decomposing the Impact of the Expenditure Components of GDP on Euro Area Unemployment. ECB Working Paper Series 1747, European Central Bank, Frankfurt.

Ball, L., Jalles, J.T., and Loungani, P. (2015). Do Forecasters Believe in Okun's Law? An Assessment of Unemployment and Output Forecasts. International Journal of Forecasting, 31(1), pp. 176-184. https://doi.org/10.1016/j.jforecast.2014.03.009

Ball, L., Leigh, D., and Loungani, P. (2017). Okun's Law: Fit at Fifty? Journal of Money, Credit and Banking, 49(7), pp. 1413-1441. https://doi.org/10.1111/jmcb.12420

Barreto, H., and Howland, F. (1993) There Are Two Okun's Law Relationships between Output and Unemployment. Wabash College Working Paper.

Blanchard, O., and Wolfers, J. (2000). The Role of Shocks and Institutions in the Rise of European Unemployment: The Aggregate Evidence. The Economic Journal, 110(462), pp. 1-33. https://doi.org/10.1111/1468-0297.00518

Boman, V., and Netzén Örn, A. (2017). Okun's law within the OECD: A Cross-Country Comparison, [online]. Available at: http://urn.kb.se/resolve?urn=urn:nbn:se:umu:diva-140339 [Accessed 28 Aug. 2018]

Daly, M., Fernald, J., Jordà, Ò., and Nechio, F. (2014). Interpreting Deviations from Okun's Law. FRBSF Economic Letter. [online] frbsf.org. Available at: https://www.frbsf.org/economicresearch/publications/economic-letter/2014/april/okun-law-deviation-unemploymentrecession [Accessed 29 Aug. 2018]

Daly, M., Fernald, J., Jordà, Ò., and Nechio, F. (2017). Shocks and Adjustments. FRBSF Working Paper Series. [online] frbsf.org. Available at: https://www.frbsf.org/economic-research/files/wp2013-32.pdf [Accessed 29 Aug. 2018]

Dogru, B. (2013). The Link between Unemployment Rate and Real Output in Eurozone: A Panel Error Correction Approach. Procedia - Social and Behavioral Sciences, 99, pp. 94-103. https://doi.org/10.1016/j.sbspro.2013.10.475

Economou, A., and Psarianos, I.N. (2016). Revisiting Okun's Law in European Union Countries. Journal of Economic Studies, 43(2), pp. 275-287. https://doi.org/10.1108/JES-05-2013-0063

Freeman, D.G. (2001). Panel Tests of Okun's Law for Ten Industrial Countries. Economic Inquiry, 39(4), pp. 511-523. https://doi.org/10.1093/ei/39.4.511

Guisinger, A.Y., Hernandez-Murillo, R., Owyang, M., and Sinclair, T.M. (2018). A State-Level Analysis of Okun's Law. Regional Science and Urban Economics, 68, pp. 239-248. https://doi.org/10.1016/j.regsciurbeco.2017.11.005

IMF (International Monetary Fund) (2010). Chapter 3. Unemployment Dynamics during Recessions and Recoveries: Okun's Law and Beyond. In World Economic Outlook, April 2010: Rebalancing Growth. USA: International Monetary Fund. https://doi.org/10.5089/9781589069152.081 
Knotek, E.S. (2007). How Useful Is Okun's Law. Economic Review, 92(4), pp. 73-103.

Lee, J. (2000). The Robustness of Okun's Law: Evidence from OECD Countries. Journal of Macroeconomics, 22(2), pp. 331-356. https://doi.org/10.1016/S0164-0704(00)00135-X

McKinsey Global Institute (2011). An Economy That Works: Job Creation and America's Future. San Francisco: McKinsey Global Institute.

Meyer, B., and Tasci, M. (2012). An Unstable Okun's Law, Not the Best Rule of Thumb. Economic Commentary, Federal Reserve Bank of Cleveland, 7.

Mitchell, W.F. (1993). Testing for Unit Roots and Persistence in OECD Unemployment Rates. Applied Economics, 25(12), pp. 1489-1501. https://doi.org/10.1080/00036849300000153

Nickell, S. (1997). Unemployment and Labor Market Rigidities: Europe versus North America. The Journal of Economic Perspectives, 11(3), pp. 55-74. https://doi.org/10.1257/jep.11.3.55

OECD (2012). OECD Economic Outlook, Volume 2012 Issue 1. Paris: OECD Publishing. https://doi.org/10.1787/eco_outlook-v2012-1-en

Okun, A.M. (1962). Potential GNP: Its Measurement and Significance. Cowles Foundation Paper no. 190.

Owyang, M., and Sekhposyan, T. (2012). Okun's Law over the Business Cycle: Was the Great Recession All That Different? Federal Reserve Bank of St. Louis Review, 94 (5), pp. 399-418.

Perman, R. J., and Tavera, C. (2005). A Cross-Country Analysis of the Okun's Law Coefficient in Europe. Applied Economics, 37(21), pp. 2501-2513. https://doi.org/10.1080/00036840500366395

Perman, R., and Tavera, C. (2007). Testing for Convergence of the Okun's Law Coefficient in Europe. Empirica, 34(1), pp. 45-61. https://doi.org/ 10.1007/s10663-006-9025-9

Pirimova, V. (2007). Dependency between Economic Growth and Unemployment in Bulgaria. Research papers UNWE, 2, pp. 57-84.

Prachowny, M.F.J. (1993). Okun's Law: Theoretical Foundations and Revised Estimates. The Review of Economics and Statistics, 75(2), pp. 331-336. https://doi.org/10.2307/2109440

Schnabel, G. (2002). Output Trends and Okun's Law [Working Paper no. 111]. Bank for International Settlements.

Siebert, H. (1997). Labor Market Rigidities: At the Root of Unemployment in Europe. Journal of Economic Perspectives, 11(3), pp. 37-54. https://doi.org/ 10.1257/jep.11.3.37

Sögner, L., and Stiassny, A. (2002). An Analysis on the Structural Stability of Okun's Law - A Cross-Country Study. Applied Economics, 34(14), pp. 1775-1787. https://doi.org/10.1080/00036840210124180

Villaverde, J., and Maza, A. (2008). The Robustness of Okun's law in Spain, 1980-2004 Regional Evidence. Journal of Policy Modelling, 31(2), pp. 289-297. https://doi.org/10.1016/j.jpolmod.2008.09.003

\section{Online Sources}

Eurostat, National accounts (including GDP), Labour Market (including Labour Force Survey). Available at: http://ec.europa.eu [Accessed 19 Jan. 2018] 


\section{Appendix}

Figure A1 | Correlograms of the relationship between $U m R_{t}$ and $G r R_{t}$ for the individual member states of the EU-28
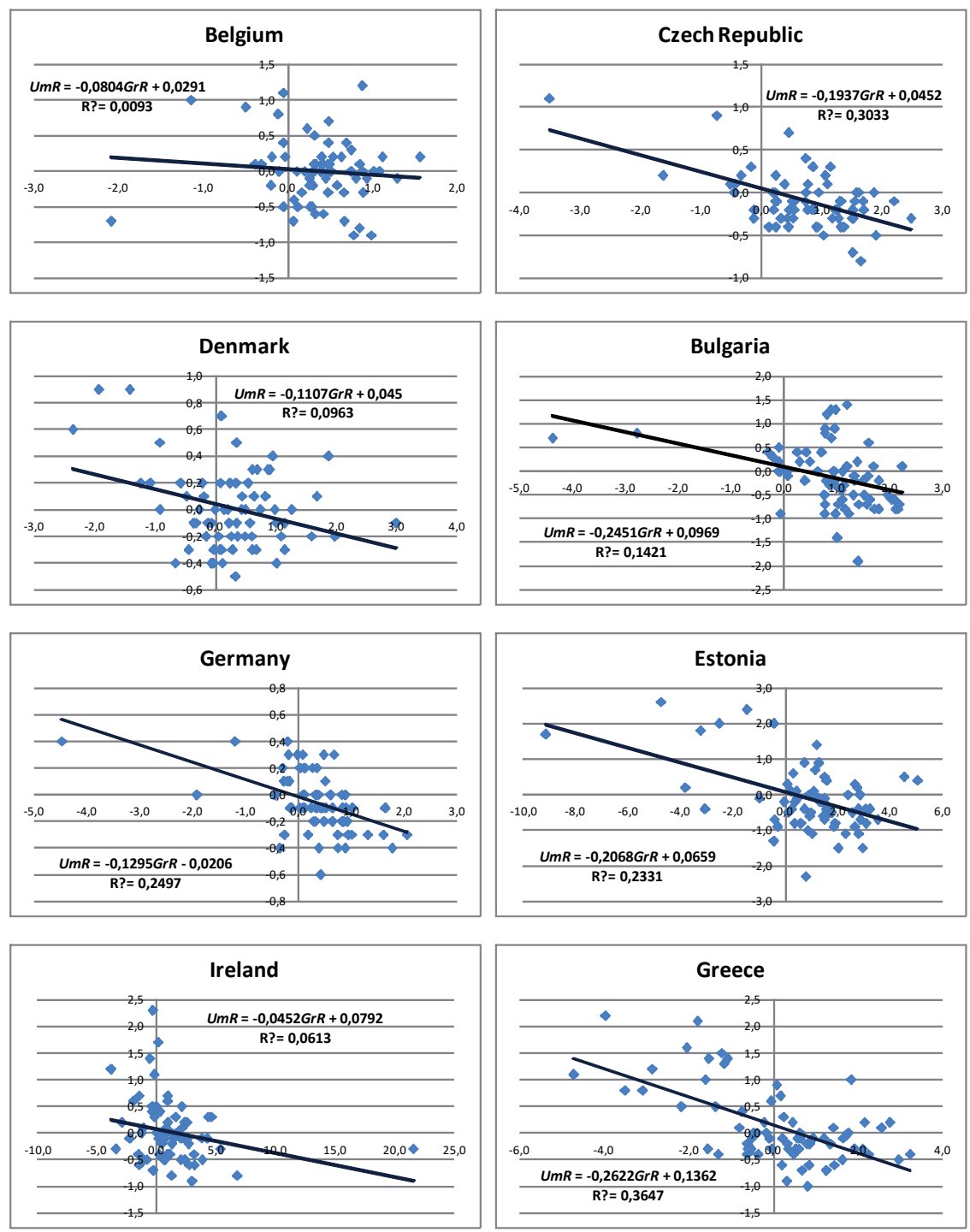

Continued on page 28 

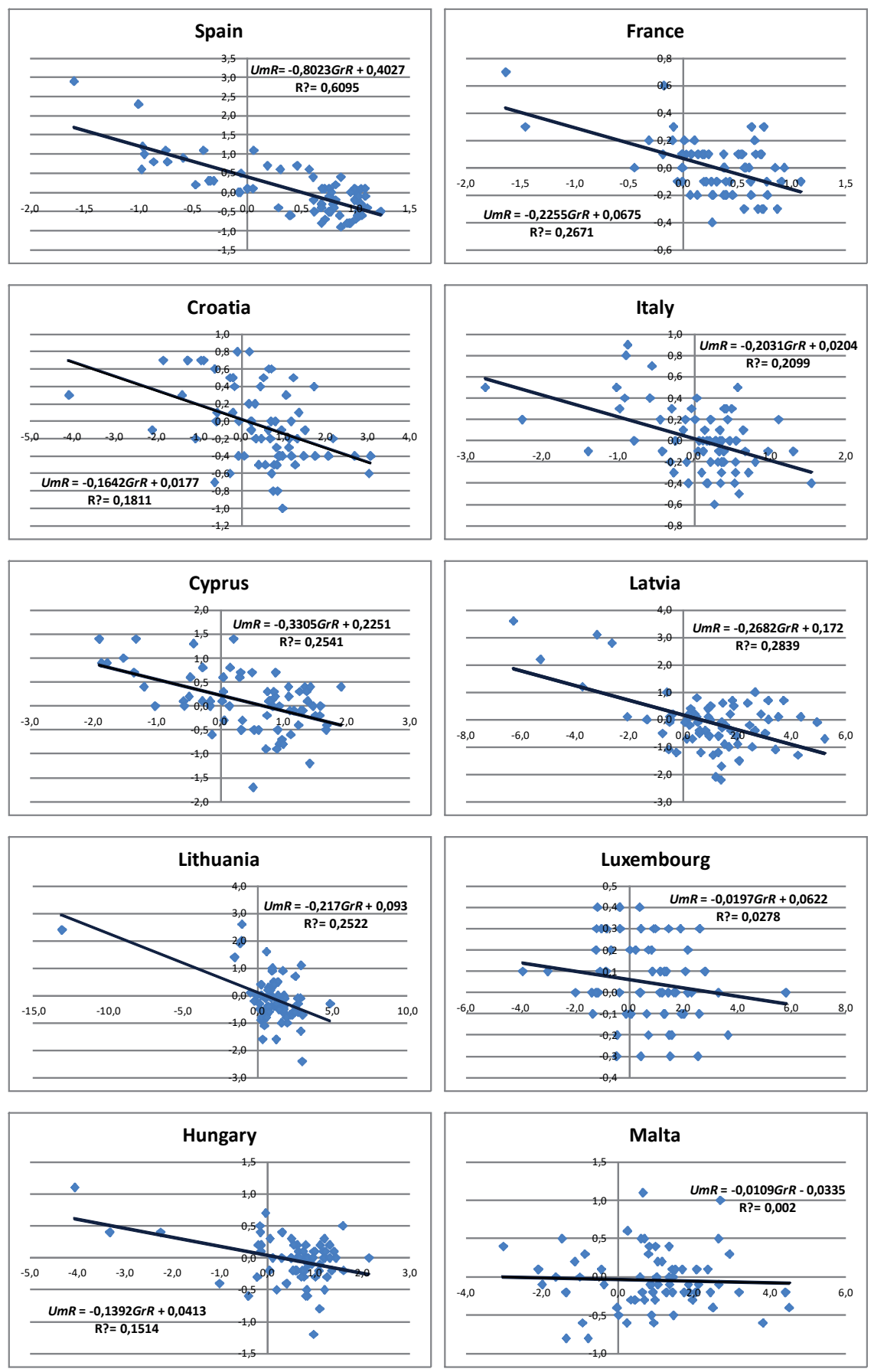

Continued on page 29 

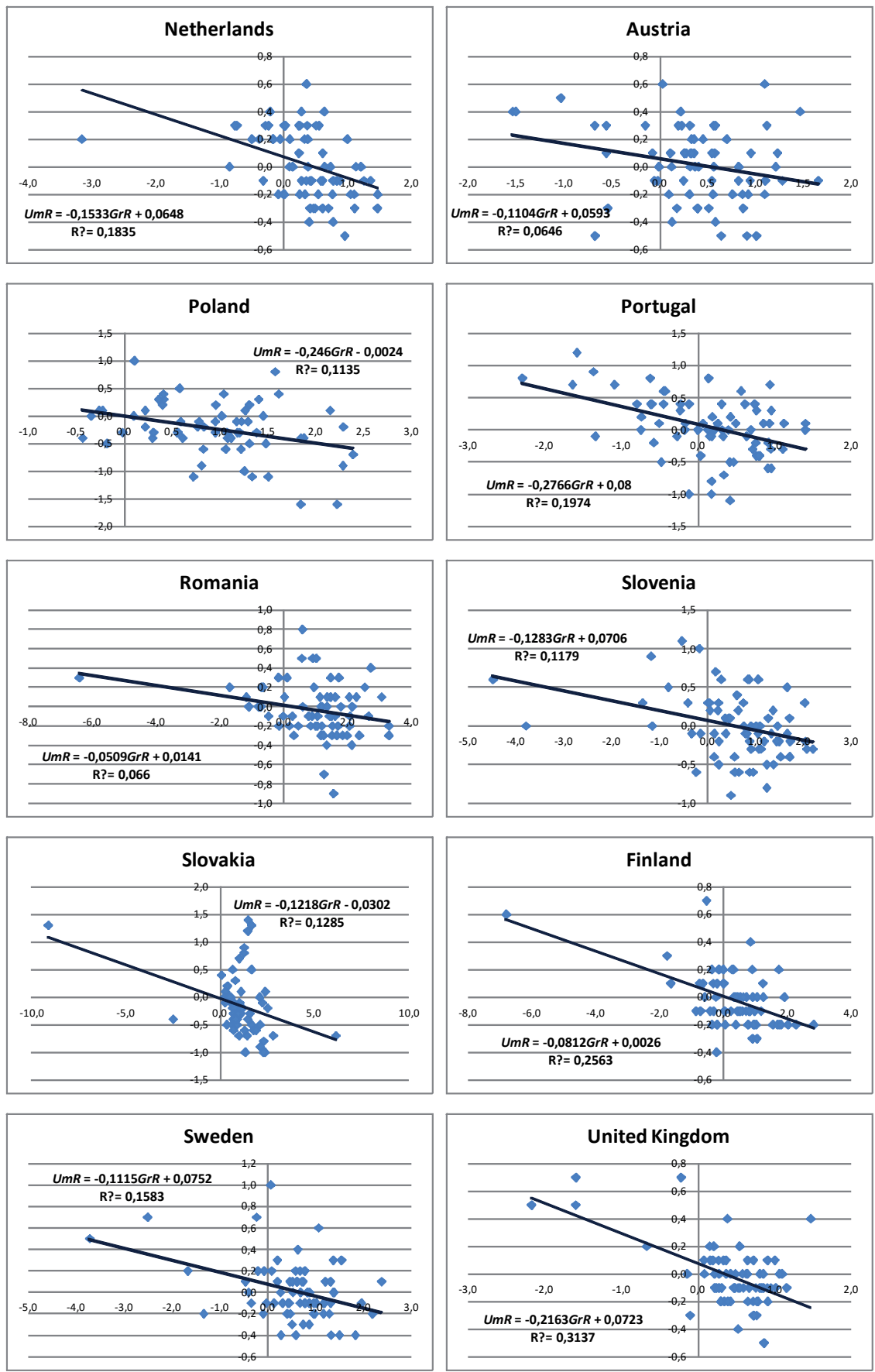

Note: The data on Poland is for the period 2002Q1-2017Q3.

Source: Eurostat and the author's own calculations 